\title{
BMJ Open Prescribing practice of pregabalin/ gabapentin in pain therapy: an evaluation of German claim data
}

\author{
Annika Viniol, ${ }^{1}$ Tina Ploner, ${ }^{2}$ Lennart Hickstein, ${ }^{2,3}$ Jörg Haasenritter, ${ }^{1}$ \\ Karl Martin Klein, ${ }^{4,5}$ Jochen Walker, ${ }^{2}$ Norbert Donner-Banzhoff, ${ }^{1}$ Annette Becker ${ }^{1}$
}

To cite: Viniol A, Ploner T, Hickstein L, et al. Prescribing practice of pregabalin/ gabapentin in pain therapy: an evaluation of German claim data. BMJ Open 2019;9:e021535. doi:10.1136/ bmjopen-2018-021535

- Prepublication history and additional material for this paper are available online. To view these files, please visit the journal online (http://dx.doi. org/10.1136/bmjopen-2018021535).

Received 20 February 2018 Revised 15 January 2019 Accepted 18 February 2019

\section{Check for updates}

(C) Author(s) (or their employer(s)) 2019. Re-use permitted under CC BY-NC. No commercial re-use. See rights and permissions. Published by BMJ.

${ }^{1}$ Department of General Medicine, Preventive and Rehabilitation Medicine, University of Marburg, Marburg, Germany

${ }^{2}$ Institute for Applied Health Research Berlin, InGef, Berlin, Germany

${ }^{3}$ University Medicine Greifswald, Greifswald, Germany

${ }^{4}$ Epilepsy Centre Frankfurt

Rhein-Main, University Hospital

Frankfurt, University of Frankfurt, Frankfurt, Hessen, Germany ${ }^{5}$ Departments of Clinical Neurosciences, University of Calgary, Calgary, Alberta, Canada

Correspondence to Dr Annika Viniol; annika.viniol@staff.unimarburg.de

\section{ABSTRACT}

Objectives To analyse the prevalence and incidence of pregabalin and gabapentin (P/G) prescriptions, typical therapeutic uses of $P / G$ with special attention to painrelated diagnoses and discontinuation rates.

Design Secondary data analysis.

Setting Primary and secondary care in Germany. Participants Four million patients in the years 2009-2015 (anonymous health insurance data).

Intervention None.

Primary and secondary outcome measures $P / G$ prescribing rates, $P / G$ prescribing rates associated with pain therapy, analysis of pain-related diagnoses leading to new $P / G$ prescriptions and the discontinuation rate of $P / G$.

Results In 2015, 1.6\% of insured persons received $P / G$ prescriptions. Among the patients with pain first treated with $P / G$, as few as $25.7 \%$ were diagnosed with a typical neuropathic pain disorder. The remaining $74.3 \%$ had either not received a diagnosis of neuropathic pain or showed a neuropathic component that was pathophysiologically conceivable but did not support the prescription of $P / G$. High discontinuation rates were observed (85\%). Among the patients who had discontinued the drug, $61.1 \%$ did not receive follow-up prescriptions within 2 years.

Conclusion The results show that $P / G$ is widely prescribed in cases of chronic pain irrespective of neuropathic pain diagnoses. The high discontinuation rate indicates a lack of therapeutic benefits and/or the occurrence of adverse effects.

\section{INTRODUCTION}

Pregabalin and gabapentin, hereinafter referred to as pregabalin/gabapentin or $\mathrm{P} / \mathrm{G}$, belong to the group of 'newer antiepileptic drugs'. As chemical analogues of the inhibitory neurotransmitter gamma-aminobutyric acid they are classified as 'gabapentinoids'. Originally developed for the treatment of epilepsy, the European Medicines Agency approved $\mathrm{P} / \mathrm{G}$ also for the treatment of neuropathic pain (pregabalin (2004): 'peripheral and central neuropathic pain'; gabapentin (2001): 'peripheral neuropathic pain-like painful diabetic neuropathy and postherpetic neuralgia ${ }^{1}$ ), which is now a common indication for their prescription. $^{2}$

\section{Strengths and limitations of this study}

Secondary data analysis can lead to systematic restrictions.

- Diagnosis may have been coded incorrectly, resulting in either underestimation or overestimation of neuropathic diagnoses.

- According to the secondary nature of our data, we cannot conclude about the reasons of the detected prescribing practice.

- We have no information about the discontinuation reasons of pregabalin and gabapentin $(\mathrm{P} / \mathrm{G})$.

- Our methodological approach does not include off-label indications of $P / G$.

Randomised controlled studies reported a slight improvement in specific forms of neuropathic pain disorder for patients treated with $\mathrm{P} / \mathrm{G}$ compared with placebo. ${ }^{3-5}$ However, the obviously rather weak therapeutic effects of $\mathrm{P} / \mathrm{G}$ and their comparatively small application area are contradicted by the prescription figures, which have been increasing steadily over the recent years. According to the German 'medication report' from Schwabe and Paffrath (based on statutory health insurance data), a total of 128 million daily doses of $\mathrm{P} / \mathrm{G}$ were prescribed in $2015 .^{2}$ In 2015 , Pfizer's product Lyrica (pregabalin) was ranked 26th on the list of the highest revenue medicines under patent protection and produced net costs of 170.3 million Euro for the statutory health insurance. ${ }^{2}$ US Prescription data describe the same trends: from 2012 to 2016, the prescription rate of gabapentin increased from 39 to 64 million annual prescriptions. ${ }^{67}$

In view of this general trend, we intended to further investigate the prescribing practices. This study aims to address the following points in question:

1. The annual prevalence for the prescription of $\mathrm{P} / \mathrm{G}$ among all insured persons from 2009 to 2015. 
2. The annual incidence for new prescriptions of $\mathrm{P} / \mathrm{G}$ among all insured persons from 2009 to 2015.

3. The indications for new $\mathrm{P} / \mathrm{G}$ prescriptions (epilepsy/ generalised anxiety disorder/pain) from 2009 to 2015.

4. The pain-related diagnoses (neuropathic pain/ non-neuropathic pain/mixed pain/no pain) that lead to new $\mathrm{P} / \mathrm{G}$ prescriptions to patients without epilepsy in 2015 .

5. The proportion of patients who discontinued $\mathrm{P} / \mathrm{G}$ treatment within 2 years after its new prescription for pain management and the proportion of follow-up prescriptions after discontinuation.

\section{METHODS}

\section{Study design and database}

For this project, the Institute for Applied Health Research (InGef) database was analysed in a cross-sectional design. This research database (formerly HRI Research Database) contains anonymous data on the utilisation and resource consumption of approx. 6.7 million insured persons from about 65 health insurance funds and company health insurance funds. ${ }^{8}$ As long as the insured persons are members of these health insurances, their data are all-encompassing available without overlap with other databases, which also means that if a person changes to an insurance that is not included, his or her data become unavailable. The present analysis is based on a random sample of almost 4 million data sets which closely represents the age and gender structure in Germany for the year 2013 (according to DestatisFederal Statistical Office-31 December 2013). The random sampling enables a longitudinal analysis of insured persons over the years 2009-2015. Besides sociodemographic data, it contains central pharma numbers (PZN) and Anatomical Therapeutic Chemical classification (ATC) codes, International Classification of Diseases (ICD) diagnoses from outpatient and inpatient areas as well as invoiced medical services. These data give information on medications prescribed by doctors and dispensed by pharmacies.

The diagnoses and prescriptions can be linked to the anonymous insured person's identification code at the end of each quarter. Each analysis included all dosage forms and formulations of $\mathrm{P} / \mathrm{G}$.

\section{Random sample analysis}

The following inclusion criteria vary according to the point in question:

\section{Sample 1 (annual prevalence)}

Persons who were insured for at least 1 day in the first quarter of the respective reporting year.

\section{Sample 2 (annual incidence)}

Persons who were insured for at least 1 day in the first quarter of the respective reporting year and 365 days in the previous year.
Sample 3 (indications for new prescription)

Persons who were insured for at least 1 day in the first quarter of the respective reporting year and 365 days in the previous year with at least one $\mathrm{P} / \mathrm{G}$ prescription (ATC code: N03AX12 or N03AX16) in the reporting year, but not in the four previous quarters (independent from diagnosis).

\section{Sample 4 (pain diagnoses, new prescription)}

Persons who were insured for at least 1 day in the first quarter of 2015 and fulfil the following criteria: no coded epilepsy diagnosis (G40.- I G41.-) in the years 2014-2015; no prescription of antiepileptic medication (all N03 codes) in 2014; at least one $\mathrm{P} / \mathrm{G}$ prescription (ATC code: N03AX12 or N03AX16) in 2015.

\section{Sample 5 (discontinuation, new prescription)}

Persons who were insured for at least 1 day in the first quarter of 2013 and fulfil the following criteria: no coded epilepsy diagnosis (G40.- I G41.-) in the years 2011-2013; no prescription of antiepileptic medication (all N03 codes) in the years 2011-2012; at least one P/G prescription (ATC code: N03AX12 or N03AX16), and at least one pain diagnosis in the same quarter of the prescription in 2013.

\section{Data evaluation}

The annual prevalence was calculated individually for each reporting year from 2009 to 2015. The total of insured persons who received at least one $\mathrm{P} / \mathrm{G}$ prescription (ATC code: N03AX12 or N03AX16) within 1 year was divided by the number of all insured persons from sample 1 of the respective reporting year.

The annual incidence was calculated individually for each year from 2010 to 2015 (except for the first reporting year 2009, as due to the lack of data for the previous year, new prescriptions could not be identified). To this end, all insured persons who had received a $\mathrm{P} / \mathrm{G}$ prescription (ATC code: N03AX12 or N03AX16) within 1 year, but not in the previous year, were compared with the total number of all patients from sample 2 of the respective reporting year.

The areas of indications for $\mathrm{P} / \mathrm{G}$ prescribing were analysed individually for each possible combination of the diagnoses 'epilepsy (G40.- I G41.-)','generalised anxiety disorder (F41.1)' and 'pain (all ICD- codes of pain syndromes)" (for the pain-related ICDs included, see online supplementary file 1 ). In addition, the number of insured persons from sample 3 that were falling into one of these diagnosis groups and had concurrently received a $\mathrm{P} / \mathrm{G}$ prescription within a quarter was divided by the number of all insured persons in sample 3 . These calculations were applied to each reporting year from 2010 to 2015.

To answer question 4, we first analysed the percentage distribution of all coded ICD-10 pain diagnoses of the insured persons from sample 4, then classified the diagnoses into the following categories: 
Table 1A Annual prevalence rates of pregabalin/ gabapentin (P/G) prescriptions, 2009-2015

\begin{tabular}{llll}
\hline & $\begin{array}{l}\text { Number } \\
\text { of insured } \\
\text { persons } \\
\text { with P/G } \\
\text { prescriptions }\end{array}$ & $\begin{array}{l}\text { Total number } \\
\text { of insured } \\
\text { persons }\end{array}$ & $\begin{array}{l}\text { Prevalence } \\
\text { per 100000 } \\
\text { insured } \\
\text { persons }\end{array}$ \\
\hline Year & 41083 & 3822333 & 1074.8 \\
\hline 2009 & 46225 & 3890247 & 1188.2 \\
\hline 2010 & 50230 & 4027591 & 1247.1 \\
\hline 2011 & 53389 & 4019944 & 1328.1 \\
\hline 2012 & 56358 & 4010383 & 1405.3 \\
\hline 2013 & 60306 & 3998004 & 1508.4 \\
\hline 2014 & 61828 & 3870869 & 1597.3 \\
\hline 2015 & & 3948482 & 1335.6 \\
\hline Mean value & 52774 & & \\
\hline $2009-2015$ & & & \\
\hline
\end{tabular}

Table 1B Prevalence rates of pregabalin/gabapentin prescriptions in 2015, stratified by age and gender

\begin{tabular}{|c|c|c|c|}
\hline $\begin{array}{l}\text { Age } \\
\text { group }\end{array}$ & $\begin{array}{l}\text { Total } \\
\text { prevalence per } \\
100000 \text { insured } \\
\text { persons }\end{array}$ & $\begin{array}{l}\text { Prevalence } \\
\text { per } 100000 \\
\text { insured } \\
\text { women }\end{array}$ & $\begin{array}{l}\text { Prevalence } \\
\text { per } 100000 \\
\text { insured men }\end{array}$ \\
\hline $0-17$ & 13.4 & 17.5 & 9.6 \\
\hline 18-35 & 249.2 & 289.4 & 210.0 \\
\hline $36-55$ & 1042.5 & 1213.2 & 874.9 \\
\hline 56-75 & 2899.6 & 3146.0 & 2634.9 \\
\hline $76+$ & 5302.1 & 5709.5 & 4658.1 \\
\hline Total & 1597.3 & 1869.7 & 1312.8 \\
\hline Total 18+ & 1894.0 & 2197.1 & 1571.7 \\
\hline
\end{tabular}

1. Diagnoses with an improved evidence for $\mathrm{P} / \mathrm{G}$ (assessed by the authors via controlled randomised studies) were classified as 'typical neuropathic pain disorders with demonstrable benefit from $\mathrm{P} / \mathrm{G}$ therapy'. ${ }^{2-5}$

2. Diseases from a potentially neuropathic genesis based on aetiology/anatomical deliberations, without therapeutic benefit of $\mathrm{P} / \mathrm{G}^{9}$ were classified as 'pain, possibly of neuropathic or partial-neuropathic cause for which there is no demonstrable benefit of $\mathrm{P} / \mathrm{G}$ '.

3. All other pain diagnoses were labelled as 'non-neuropathic pain'.

To calculate the number of follow-up prescriptions and the rate of discontinuation according to new $\mathrm{P} / \mathrm{G}$ prescriptions, we analysed the sample 5 data from the year 2013 plus a follow-up observation period of 2 years (until 2015). Cases in which the patient had not received a $\mathrm{P} / \mathrm{G}$ prescription within at least two consecutive quarters, including the 2-year follow-up period, were defined as discontinuation of therapy. This evaluation revealed the percentage of insured persons who discontinued therapy and the number of individual prescriptions before termination.
Patient and public involvement

Because the present study represents a retrospective secondary data analysis, patients and the public were not directly involved. Our work includes the presentation of our research at scientific conferences.

\section{RESULTS}

\section{Prevalence and incidence of P/G prescriptions}

From 2009 to 2015, 1.3\% (52 774/3 948 482) of insured persons received at least one $\mathrm{P} / \mathrm{G}$ prescription. As shown in table $1 \mathrm{~A}$, the prevalence rate increased from $1.1 \%$ in 2009 to $1.6 \%$ per annum in 2015.

In table $1 \mathrm{~B}$, we present the prevalence rates in the year 2015 stratified by age and gender. The highest prescription rate was seen in the age group 76+ (5302 persons per 100000 insured persons in 2015). In contrast, the prescription rate for minors was comparatively low (13.4 per 100000 insured persons), $\mathrm{P} / \mathrm{G}$ was prescribed more frequently to women than to men (women: a total of 1869.7 per 100000 insured persons; men: a total of 1312.8 per 100000 insured persons).

Table 2 shows the annual incidence of $\mathrm{P} / \mathrm{G}$ prescriptions from 2010 to 2015. As the prescription rate in general, the rate of new $\mathrm{P} / \mathrm{G}$ prescriptions increased annually (table 2 ).

\section{Areas of application}

As mentioned earlier, $\mathrm{P} / \mathrm{G}$ is approved for three applications: epilepsy, anxiety disorders and neuropathic pain. However, our results show that that the majority $(77.9 \%)$ of $\mathrm{P} / \mathrm{G}$ recipients had only received a diagnosis of pain but had suffered neither from epilepsy nor anxiety disorder (table 3 ).

In $11.6 \%$ of the cases, there was no evidence for any of the approved diagnoses for $\mathrm{P} / \mathrm{G}$ prescription. $\mathrm{P} / \mathrm{G}$ recipients who were diagnosed exclusively with epilepsy or anxiety (epilepsy: $1.3 \%$; anxiety $1.1 \%$ ) were in the minority. Although the incidence of $\mathrm{P} / \mathrm{G}$ prescriptions (excluding pain diagnoses) have increased continuously over the years, the proportion of epilepsy and anxiety

Table 2 Annual incidence rates for new pregabalin/ gabapentin (P/G) prescriptions 2010-2015

\begin{tabular}{llll}
\hline & $\begin{array}{l}\text { Number of } \\
\text { insured persons } \\
\text { with new P/G } \\
\text { prescriptions }\end{array}$ & $\begin{array}{l}\text { Total number } \\
\text { of insured } \\
\text { persons }\end{array}$ & $\begin{array}{l}\text { Incidence } \\
\text { per 100000 } \\
\text { insured } \\
\text { persons }\end{array}$ \\
\hline Year & 22776 & 3701696 & 615.3 \\
\hline 2010 & 23121 & 3717582 & 621.9 \\
\hline 2011 & 24750 & 3977347 & 622.3 \\
\hline 2012 & 25784 & 3966813 & 650.0 \\
\hline 2013 & 27613 & 3952306 & 698.7 \\
\hline 2014 & 26526 & 3757502 & 705.9 \\
\hline 2015 & 25095 & 3845541 & 652.4 \\
\hline Mean value & & & \\
\hline
\end{tabular}


Table 3 Diagnostic reasons for pregabalin/ gabapentin (P/G) prescriptions in $2015(n=61828)$

\begin{tabular}{lcc}
\hline & $\begin{array}{l}\text { Number of insured } \\
\text { persons with P/G }\end{array}$ \\
\hline ICD diagnoses & 48190 & $\%$ \\
\hline Pain* (exclusive) & 793 & 77.9 \\
\hline Epilepsy† (exclusive) & 707 & 1.3 \\
\hline Anxiety disorder $¥$ (exclusive) & 2404 & 1.1 \\
\hline Pain+anxiety disorder & 2222 & 3.9 \\
\hline Pain+epilepsy & 162 & 0.6 \\
\hline $\begin{array}{l}\text { Pain+epilepsy+anxiety } \\
\text { disorder }\end{array}$ & 49 & 0.1 \\
\hline $\begin{array}{l}\text { Epilepsy+anxiety disorder } \\
\text { No pain, epilepsy or anxiety }\end{array}$ & 7198 & 11.6 \\
disorder & & \\
\hline
\end{tabular}

*All ICD-10 pain diagnoses listed in the supplementary information.

†ICD codes: G40.- | G41.-.

†ICD codes: F41.1.

diagnoses remained relatively constant in the new $\mathrm{P} / \mathrm{G}$ prescriptions group.

\section{$P / G$ application in patients with pain}

After the number of patients with epilepsy were excluded, 25251 insured persons with new $\mathrm{P} / \mathrm{G}$ prescriptions remained. For these, we determined the type of pain diagnoses. As presented in table 4 , it appears that one quarter of all new $\mathrm{P} / \mathrm{G}$ recipients $(25.7 \%$ [line $\mathrm{B}+\mathrm{D}+\mathrm{F}+\mathrm{G}])$ were diagnosed with typical neuropathic pain.

Table 4 Pain-related diagnoses in patients with new pregabalin/gabapentin (P/G) prescriptions in $2015(n=25251)$

\begin{tabular}{|c|c|c|c|c|}
\hline \multicolumn{3}{|c|}{ Pain-related diagnoses } & \multirow{2}{*}{$\begin{array}{c}\begin{array}{l}\text { Number } \\
\text { of insured } \\
\text { persons }\end{array} \\
2951\end{array}$} & \multirow{2}{*}{$\begin{array}{l}\% \\
11.7\end{array}$} \\
\hline$A$ & 1 & $\begin{array}{l}\text { Non-neuropathic pain } \\
\text { (exclusive) }\end{array}$ & & \\
\hline$B$ & 2 & $\begin{array}{l}\text { Typical neuropathic pain } \\
\text { disorder (exclusive) } \\
\text { (demonstrable benefit of } \\
\text { a P/G therapy) }\end{array}$ & 1218 & 4.8 \\
\hline C & 3 & $\begin{array}{l}\text { Pain with possible } \\
\text { neuropathic or partial- } \\
\text { neuropathic cause } \\
\text { (exclusive) } \\
\text { (no demonstrable benefit } \\
\text { of } P / G \text { ) }\end{array}$ & 3025 & 12.0 \\
\hline$D$ & $1+2$ & & 1295 & 5.1 \\
\hline$E$ & $1+3$ & & 10756 & 42.6 \\
\hline $\mathrm{F}$ & $2+3$ & & 1010 & 4.0 \\
\hline G & $1+2+$ & & 2990 & 11.8 \\
\hline $\mathrm{H}$ & neithe & 1,2 nor 3 & 2006 & 7.9 \\
\hline
\end{tabular}

For the majority (70.4\% [line $\mathrm{C}+\mathrm{E}+\mathrm{F}+\mathrm{G}$ in table 4$])$ of new recipients, a neuropathic component was pathophysiologically conceivable, but there was no characteristic indication for $\mathrm{P} / \mathrm{G}$ treatment. The three most frequent examples of this category were the diagnoses 'M544 Lumboischialgia' (5836/25 251), 'M5416_Radiculopathy: Lumbar region' (4978/25 251) and 'M542_Cervical neuralgia' (4543/25 251). In 19.6\% of the cases (lines $\mathrm{A}+\mathrm{H}$ in table 4), we found only a 'non-neuropathic pain diagnosis' or 'no pain diagnosis'.

The percentage distribution of the pain-related diagnoses varied only marginally over time (typical) neuropathic pain disorders: $17.8 \%$ (2011)\%-18.6\% (2013); pain disorder with a neuropathic component: 72.4 (2011)\%-73.8\% (2013); non-neuropathic pain diagnosis/no pain diagnosis: $18.8 \%$ (2011)\%-20.6\% (2013).

\section{Discontinuation of $\mathrm{P} / \mathrm{G}$ treatment}

As many as $85 \%$ (16 573/19 501) of insured persons who had received a new $\mathrm{P} / \mathrm{G}$ prescription due to pain (excluding patients with epilepsy diagnosis) discontinued their treatment within the 2-year follow-up period. In the majority, discontinuation occurred within a short period. About $61.1 \%$ of the patients did not receive a follow-up prescription (number of follow-up prescriptions/figures in per cent: $1 / 13.2 \% ; 2 / 7.5 \% ; 3 / 5.4 \%$; $\geq 4 / 12.8 \%$ ). In contrast, as few as $15 \%$ of the insured persons received regular follow-up $\mathrm{P} / \mathrm{G}$ prescriptions (2928/19 501).

\section{DISCUSSION}

Our results reveal two contradictory trends: although the prescription figures for $P / G$ increased annually in the investigation period, only about $25 \%$ of the patients with new $\mathrm{P} / \mathrm{G}$ prescriptions showed a typical neuropathic pain disorder and a demonstrable benefit of a $\mathrm{P} / \mathrm{G}$ therapy, in many cases, resulting in discontinuation of this therapy.

These findings are in line with data from the USA. ${ }^{7}$

Although the incidence of purely neuropathic pain disorders has been slightly increasing in the last years, the increase in the $\mathrm{P} / \mathrm{G}$ prescription figures does not disproportionate. The steady rise of prescriptions indicates that $\mathrm{P} / \mathrm{G}$ is being applied progressively in patients with 'mixed chronic pain' (mixed pain). 'Mixed pain' refers to chronic pain syndromes in which a mixture of nociceptive and neuropathic pain components is assumed..$^{10} 11$

Regarding the pain diagnoses which are coded parallel to new $\mathrm{P} / \mathrm{G}$ prescriptions, the question arises which chronic pain diagnoses should be classified as neuropathic or non-neuropathic. A clear differentiation between these two definitions does not exist. The S1-guideline 'Diagnostics of neuropathic pain' (S1 level: expert group recommendation $)^{9}$ of the German Society of Neurology offers a broad catalogue of neuropathic pain diagnoses. Besides classical neuropathic pain syndromes (eg, postherpetic neuralgia) where somatosensory nerve structures are 
damaged, the authors ${ }^{9}$ also present pain diagnoses in which a neuropathic component is pathophysiologically conceivable (for example by nerve irritation in diagnosis like 'lumboischialgia' or 'radiculopathy') but do not necessarily comprise damaged nerve structures. Due to the fact that a differentiation is not therapeutically relevant ${ }^{12}$, we decided to differentiate the neuropathic pain diagnoses according to the proven benefit of P/G: 'typical neuropathic pain disorder' with a demonstrable benefit of $\mathrm{P} / \mathrm{G}$ therapy versus 'pain, possibly with neuropathic or partially neuropathic cause' with no evidence for the application of $\mathrm{P} / \mathrm{G}$.

Due to the nature of a routine data analysis, we were not able to determine the personal reasons for discontinuation. These possibilities include adverse effects or an absence of the desired pain-relieving effect. We assume that the high discontinuation rate reflects an ineffectiveness of $\mathrm{P} / \mathrm{G}$ in chronic pain therapy.

The discrepancy between the high number of prescriptions and the discontinuation rate, potentially indicating a clinically unconvincing effect, raises the question why this drug might be so readily prescribed. Due to the complex nature of the doctor-patient interaction, especially in the face of a chronic pain disorder, doctors might resort to second line medication to help their patients. Furthermore, marketing strategies of the pharmaceutical industry, ${ }^{7}$ among others, that specifically target mixedpain patients with neuropathic symptoms, may play an important role in their decision.

Altogether, the results of this analysis suggest an overprescribing of $\mathrm{P} / \mathrm{G}$. In consequence, numerous patients probably unnecessarily use medicine that is accompanied with polypharmacy risks (eg, side effects, drugdrug interactions). Furthermore, overprescribing is a high economic burden for the healthcare system. For example, the costs for pregabalin has doubled from 2012 to $\$ 4.4$ billion in 2016 in the USA ${ }^{6}{ }^{7}$ German data describe the same trends. ${ }^{2}$ This might be a possibility for savings for health insurance funds.

However, secondary data analysis, which is based on accounting data on the utilisation of insured persons from health insurance funds, can lead to systematic restrictions. ${ }^{13}$ While the variable ' $\mathrm{P} / \mathrm{G}$ consumption' can be considered a valid indicator (because $\mathrm{P} / \mathrm{G}$ is only available on prescription), the operationalisation of the pain-related diagnosis variables represents a challenge, because diagnosis coding may happen insufficient. One possible reason are random errors that occur in the course of diagnosis coding, resulting in a potential bias in both directions (diagnoses appear more or less severe than in reality). Another reason may be the fact that doctors probably prefer to code clear neuropathic diagnoses to justify the prescription even in cases where the neuropathic nature is unclear. This can result in a lower proportion of evidence-based indications. On the other hand, misclassifications of unspecific low back pain can produce an overestimation, since these diagnoses are often routinely coded as 'lumboischialgia'/'radiculopathy: lumbar region' or unspecific neck pain as 'cervical neuralgia'.

According to international literature, $\mathrm{P} / \mathrm{G}$ is sometimes also used in off-label indications like hot flush, restless leg, multiple sclerosis. ${ }^{14}$ To avoid counting these cases erroneously as non-neuropathic pain conditions, our methodological approach does not include off-label indications.

\section{CONCLUSION}

Our analysis leads to the assumption that the increasing use of $\mathrm{P} / \mathrm{G}$ is not based on the diagnosis of typical neuropathic pain conditions. Furthermore, high discontinuation rates suggest that the anticipated therapeutic effect is lacking and/or adverse effects occur. Clinicians and patients should exercise caution regarding $\mathrm{P} / \mathrm{G}$ prescriptions.

Contributors AV: planned the study, discussed the results and wrote the manuscript. TP, LH: analysed data and discussed the manuscript. KMK: gave support to study design and discussed the manuscript. JW, JH, NDB, AB: discussed the results and the manuscript.

Funding The authors have not declared a specific grant for this research from any funding agency in the public, commercial or not-for-profit sectors.

\section{Competing interests None declared.}

Patient consent for publication Not required.

Provenance and peer review Not commissioned; externally peer reviewed.

Data sharing statement Data used in the analyses are entrusted in the Institute for Applied Health Research Berlin. Please contact: jochen.walker@hrisk.de.

Author note The study protocol is available on request. Please contact: annika. viniol@staff.uni-marburg.de.

Open access This is an open access article distributed in accordance with the Creative Commons Attribution Non Commercial (CC BY-NC 4.0) license, which permits others to distribute, remix, adapt, build upon this work non-commercially, and license their derivative works on different terms, provided the original work is properly cited, appropriate credit is given, any changes made indicated, and the use is non-commercial. See: http://creativecommons.org/licenses/by-nc/4.0/.

\section{REFERENCES}

1. European medicines agency. Lyrica. http://www.ema.europa.eu/ema/ index.jsp?curl=pages/medicines/human/medicines/000546/human_ med_000894.jsp\&mid=WC0b01ac058001d124 (Accessed 17 Jul 2018).

2. Schwabe U, Paffrath D. Arzneiverordnungs-report 2016. Heidelberg: Springer, 2016

3. Wiffen PJ, Derry S, Bell RF, et al. Gabapentin for chronic neuropathic pain in adults. Cochrane Database Syst Rev 2017;6:CD007938.

4. Moore RA, Straube S, Wiffen PJ, et al. Pregabalin for acute and chronic pain in adults. Cochrane Database Syst Rev 2009;3:CD007076.

5. Backonja M, Beydoun A, Edwards KR, et al. Gabapentin for the symptomatic treatment of painful neuropathy in patients with diabetes mellitus: a randomized controlled trial. JAMA 1998;280:1831-6.

6. QuintilesIMS Institute. Medicines Use and Spendingin the U.S.: A Review of 2016 and Outlook to 2021 2017. https://structurecmsstaging-psyclone.netdna-ssl.com/client_assets/dwonk/media/ attachments/590c/6aa0/6970/2d2d/4182/0000/590c6aa069702d2d 41820000.pdf?1493985952 (Accessed 16 Jul 2018).

7. Goodman CW, Brett AS. Gabapentin and pregabalin for pain - is increased prescribing a cause for concern? N Engl J Med 2017;377:411-4.

8. Andersohn F, Walker J. Characteristics and external validity of the German Health Risk Institute (HRI) Database. Pharmacoepidemiol Drug Saf 2016;25:106-9. 
9. Deutsche Gesellschaft für Neurologie. Diagnostik neuropathischer Schmerzen: S1-Leitlinie, 2012.

10. Ibor PJ, Sánchez-Magro I, Villoria J, et al. Mixed Pain Can Be Discerned in the Primary Care and Orthopedics Settings in Spain: A Large Cross-Sectional Study. Clin J Pain 2017;33:1100-8.

11. Junker U, Baron R, Freynhagen R. Chronische Schmerzen: Das „mixed pain concept “als neue Rationale. Dtsch Arzteb/ 2004;101:A1393 / B-1158 / C-1115.
12. Mathieson S, Maher CG, McLachlan AJ, et al. Trial of pregabalin for acute and chronic sciatica. N Engl J Med 2017;376:1111-20.

13. Laux G. Grenzen und Chancen der Verwendung von Routinedaten für die Versorgungsforschung. In: Versorgungsforschung in der Hausarztpraxis. Ergebnisse aus dem CONTENT-Projekt 2006 bis 2009.

14. Hamer AM, Haxby DG, McFarland BH, et al. Gabapentin use in a managed medicaid population. J Manag Care Pharm 2002;8:266-71. 